\title{
Validación de un algoritmo de obtención de biomarcadores de imágenes dinámicas de perfusión en tomografía computarizada
}

\section{Validation of an algorithm for computation of biomarker from perfusion CT images}

\author{
Félix Navarro Guirado ${ }^{1}$, José A Martín-Viera Cueto ${ }^{1}$, Mar Roca Sogorb² ${ }^{2}$ Ángel Alberich Bayarri² \\ 1 Hospital Universitario Regional de Málaga Avda. Carlos Haya. 29010 Málaga. \\ 2 QUIBIM, S.L., Avenida Aragón, 30. 46021 Valencia.
}

Fecha de Recepción: 26/02/2020 - Fecha de Aceptación: 11/11/2020

\begin{abstract}
A partir del análisis de las imágenes dinámicas de perfusión de contraste en tomografía computarizada, se pueden obtener parámetros que miden características fisiológicas relacionadas con la permeabilidad de los tejidos. Puesto que no existen elementos patrón con los que realizar calibraciones de los conjuntos de herramientas de adquisición y procesado, es necesario hacer una validación de los resultados obtenidos con el algoritmo aplicado a imágenes sintéticas. En este texto se estudia el desempeño en condiciones ideales y en presencia de ruido de un algoritmo de ajuste no lineal para la obtención de parámetros del modelo de Tofts extendido para imágenes de perfusión dinámica. En las pruebas se utiliza como fuente de datos unas imágenes sintéticas formadas a partir de valores conocidos de los parámetros del modelo.
\end{abstract}

Palabras clave: Perfusión, biomarcador, radiómica, TC.

Several physiologic characteristics related with permeability of tissues can be obtained from the analysis of dynamic images of the perfusion of contrast agent in CT images. Since there are no reference materials to calibrate both acquisition and processing tools, analysing digital reference objects is necessary in order to test them. The accuracy and precision of a non-linear fitting algorithm for the analysis of perfusion CT images using the extended Tofts model are reported in this text. Tests are performed using synthetic images where the parameters of the model are known.

Key words: Perfusion, biomarker, radiomics, CT.

\section{Introducción}

Los tratamientos oncológicos basados en radioterapia o quimioterapia tienen como uno de los objetivos principales dañar las cadenas de ADN del núcleo de las células tumorales, provocando su muerte o la de sus descendientes. ${ }^{1}$ Puesto que uno de los caminos principales para provocar este daño es la radiólisis del agua y la propagación de los radicales hasta estas cadenas mediante reacciones con el oxígeno, ${ }^{1}$ la hipoxia es una dificultad para garantizar el éxito de los tratamientos.

Para medir la hipoxia de los tejidos mediante herramientas no invasivas se puede recurrir a los análisis de imágenes de perfusión de contraste (DCE, del inglés, Dynamic Contrast Enhanced). ${ }^{2}$ Las imágenes DCE se pueden obtener usando varias modalidades, entre ellas la tomografía computarizada (TC). El análisis de las imágenes DCE puede ser semicuantitativo, estudiando la variación de la concentración de contraste en el tumor, o cuantitativo relacionando la concentración de contraste en el tumor y en un vaso relevante cercano a éste mediante un modelo farmacocinético. ${ }^{3}$ A partir de los análisis semicuantitativos y cuantitativos se pueden obtener parámetros que miden las características de la microvascularización del tejido.

Para realizar tanto análisis semicuantitativos como cuantitativos es necesario medir la concentración de

*Correspondencia: felix.navarro.sspa@juntadeandalucia.es https://doi.org/10.37004/sefm/2020.21.2.005 
contraste en cada vóxel de las imágenes, convirtiendo los valores de intensidad a valores de concentración. Aunque existen diseños de maniquíes que permiten determinar la exactitud de la medida de la concentración de contraste tanto para flujos del orden de los medidos en arterias como en tejidos poco vascularizados $^{4,5}$ o que permiten modificar la permeabilidad, ${ }^{6}$ hasta donde conocen los autores de este texto no existen elementos patrón con los que realizar una calibración del proceso completo de obtención de los parámetros del tejido.

La Sociedad norteamericana de radiología (RSNA) ha creado un grupo de trabajo llamado Quantitative Image Biomarkers Alliance (QIBA). Este grupo ha propuesto una serie de pruebas que deben hacerse a los programas que realizan el proceso de las imágenes DCE para caracterizar su desempeño. ${ }^{7}$ Aunque estas pruebas están orientadas a las imágenes DCE obtenidas por resonancia magnética (DCE-RM), se puede realizar un proceso idéntico con las imágenes de TC (DCE-TC). En este proceso de verificación se recurre a unas imágenes sintéticas de las que se conocen los parámetros del tejido que deberían obtenerse. Hasta la fecha de edición de este texto, QIBA proporciona estas imágenes patrón para DCE-RM, pero no para DCE-TC.

Para los estudios cuantitativos existen numerosos modelos farmacocinéticos adaptados a distintos tejidos. ${ }^{8}$ Uno muy usado por ser versátil y relativamente sencillo, es el modelo de Tofts extendido. ${ }^{9}$ En todos estos modelos se simplifica el contenido de cada vóxel utilizando una representación muy elemental del tejido basada en compartimentos. En el modelo de Tofts extendido se representa al tejido mediante una fracción formada por un compartimento plasmático vascular $\left(v_{p}\right)$ y otra fracción formada por el compartimento correspondiente al espacio extracelular y extravascular $\left(v_{e}\right)$. El resto del tejido está formado por células cuya participación en el flujo del contraste es despreciable. También se supone que ambos compartimentos intercambian contraste a una tasa simétrica ( $K^{\text {trans }}$ ) y que existe un flujo sanguíneo elevado. Esta última suposición implica que la concentración de contraste en el plasma del compartimento vascular $\left(c_{p}\right)$ es el mismo que el que se puede medir estudiando la señal de la arteriola que alimenta el tejido de interés (AIF, del inglés, Arterial Input Function) salvo por una corrección debida a la diferencia en las fracciones de hematocrito en vasos grandes y microcapilares $\left(F_{\text {corr }}\right)$. Mediante las ecuaciones diferenciales que definen el flujo de contraste entre compartimentos se obtiene una función de transferencia que representa la relación entre $c_{p}$ y la concentración que se puede medir en el tejido $\left(c_{t}\right)$. Esta función de transferencia contiene los parámetros $v_{p}, v_{e}$ y $K^{\text {trans }}$ que representan las características del tejido.

Para obtener los parámetros de la función de transferencia estos autores han recurrido a un algoritmo ajuste no lineal. En este texto se describen las pruebas realizadas al programa desarrollado para determinar la exactitud y precisión de sus resultados al procesar imágenes sintéticas de prueba, tanto en condiciones ideales como en presencia de ruido blanco, y los resultados obtenidos. También se describen las pruebas realizadas para caracterizar el desempeño del programa ante datos contaminados con ruido.

\section{Materiales y métodos}

\subsection{Programa bajo pruebas}

Se evaluó el funcionamiento de un programa de desarrollo propio, programado en lenguajes $R^{10}$ y Matlab (Mathworks Inc, Natick MA, EEUU).

El programa procesa series temporales de concentración de contraste $c_{t}$ obtenidas de series de imágenes DCE-TC. Con las concentraciones $c_{t}$ y $c_{p}$ realiza un análisis cuantitativo utilizando el modelo extendido de Tofts, en el que se considera que $c_{t}$ se relaciona con $c_{p}$ mediante la siguiente ecuación: ${ }^{7}$

$$
\begin{aligned}
c_{t}(t) & =F_{\text {corr }} \cdot c_{p}(t) \otimes\left(v_{p} \cdot \delta\left(t-t_{d}\right)+K^{\text {trans }} e^{-\frac{\text { Krtans }}{v_{e}}\left(t-t_{d}\right)}\right) \\
F_{\text {corr }} & =\frac{1-H C T_{v g}}{1-H C T_{v p}}
\end{aligned}
$$

donde $F_{c o r r}$ es el factor de corrección por la diferencia de fracción de hematocrito entre vasos grandes y pequeños, $\delta(t)$ es la función delta de Dirac, $t_{d}$ el tiempo de tránsito del contraste desde el vaso donde se mide $c_{p}$ hasta el vóxel donde se midió $c_{t}, \otimes$ es el operador convolución, $H C T_{v g}$ es la fracción de hematocrito para vasos grandes y $H C T_{v p}$ es la fracción de hematocrito para vasos pequeños.

El programa recibe como entrada una hipermatriz con los valores de las concentraciones de contraste pertenecientes a las imágenes DCE-TC a analizar, un vector de valores muestreados de $c_{p}$, otro con los instantes en los que se han adquirido las imágenes, y una máscara en forma de matriz tridimensional binaria (cuyos elementos son 0 o 1 ) que representa las posiciones de la región de interés (ROI) que se quiere procesar. El programa devuelve como salida cuatro mapas tridimensionales: uno donde cada vóxel indica el valor de $v_{p}$, otro de valores de ve, otro para $K^{\text {trans }}$ y otro para $t_{d}$. Los parámetros del modelo para cada vóxel se obtienen mediante un ajuste no lineal utilizando la ecuación (1) y minimizando el error cuadrático medio.

Para mejorar el desempeño con concentraciones provenientes de imágenes DCE-TC reales en las 
que hay ruido, el programa incluye un filtro basado en el análisis de componentes principales (PCA). ${ }^{11}$ Este filtro realiza un cambio de base a la obtenida mediante diagonalización de la matriz de covarianza de las series temporales de la ROI, según se describen Balvay et al., ${ }^{11}$ e identifica y elimina las componentes principales dominadas por el ruido. El programa bajo pruebas permite desactivar el filtro PCA mediante un parámetro de entrada.

\subsection{Procedimiento de validación}

Para caracterizar el desempeño del programa se compararon los parámetros obtenidos al procesar unas imágenes sintéticas generadas con parámetros conocidos del modelo. Además, para conocer el desempeño en condiciones reales, se realizaron pruebas con imágenes sintéticas a las que se añadió ruido similar al esperado en las exploraciones a pacientes.

QIBA proporciona maniquíes virtuales para DCE para poder realizar la validación de los códigos para análisis cuantitativos de imágenes DCE-RM. Para el caso del modelo de Tofts extendido, el maniquí consta de una serie de imágenes de referencia con todas las combinaciones de seis valores representativos de $K^{\text {trans }}$, tres de $v_{e}$ y seis de $v_{p}$, generando 108 regiones en total, con 661 puntos temporales por cada vóxel. El maniquí incluye también una AIF asociada.

Hasta la fecha QIBA no ha publicado ningún maniquí virtual para el caso de los códigos DCE-CT, por lo que se ha procedido a diseñar uno similar para poder caracterizar el desempeño del código. La AIF utilizada para generar el maniquí virtual se ha medido en la arteria cerebral anterior izquierda de un paciente con metástasis cerebral de un cáncer epidermoide de pulmón a partir de las imágenes obtenidas en la misma sesión que la TC de simulación para un tratamiento de radioterapia estereotáctica fraccionada.

\subsubsection{Adquisición y determinación experimental de la AIF}

Un caso ideal para las exploraciones DCE lo constituyen los estudios realizados sobre lesiones alojadas

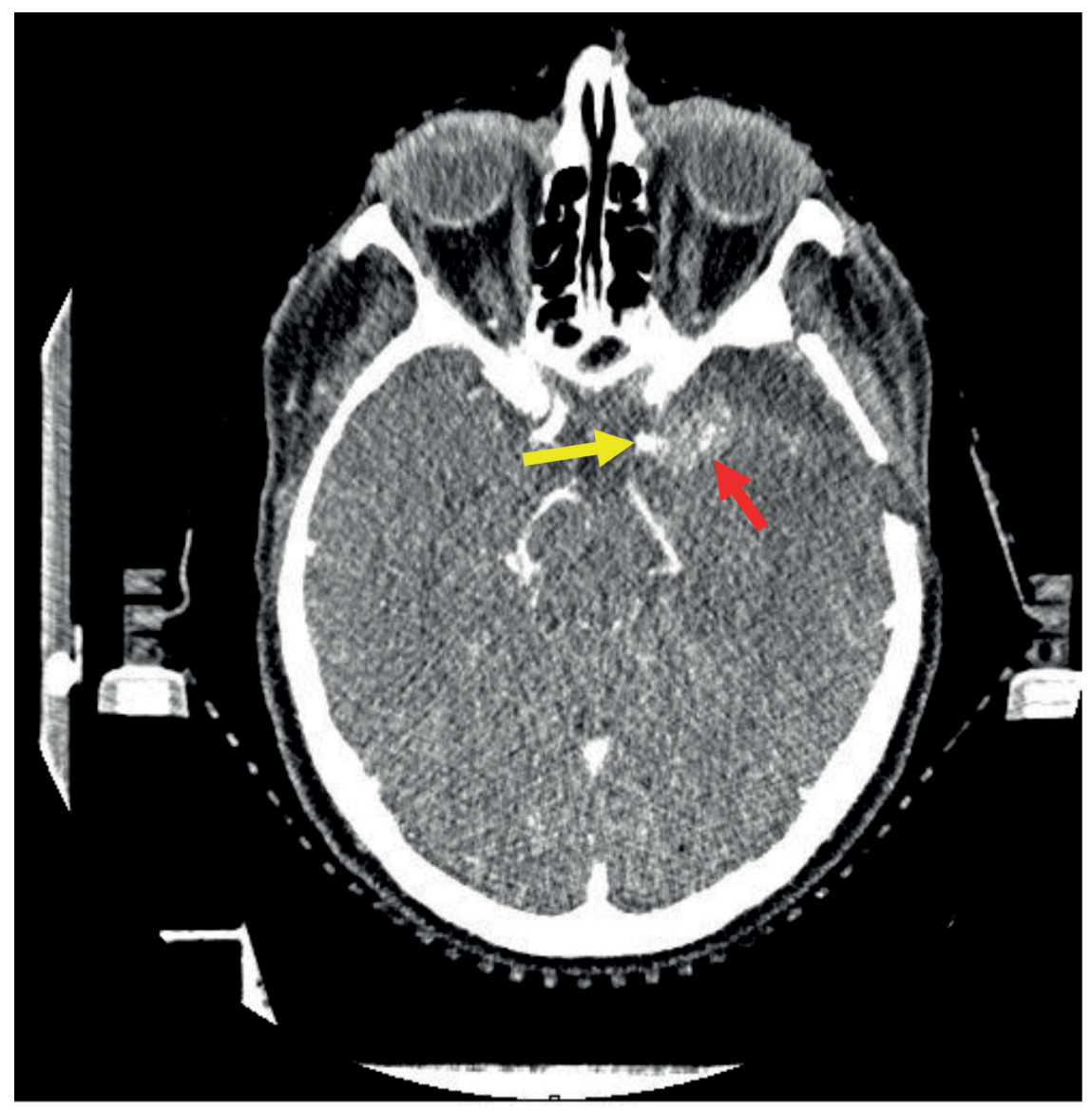

Fig. 1. Imagen del paciente del que se obtuvo la AIF 24 segundos después de la inyección del agente de contraste. La flecha amarilla indica el vaso donde se midió la AIF, la flecha roja apunta hacia la metástasis. 
en el cerebro en las que se utilice inmovilizador, ya que se elimina la necesidad de realizar alineaciones dentro de la misma serie para poder corregir el movimiento de los volúmenes de interés durante la adquisición, lo que proporciona estimaciones de la AIF con menor incertidumbre.

La función $c_{p}(t)$ se obtuvo a partir de una serie de 90 imágenes dinámicas de una exploración de cráneo de un paciente que usó una máscara para radioterapia estereotáctica fraccionada (BrainLAB, Feldkirchen, Germany). Estas imágenes fueron obtenidas en un equipo TC Aquilion LB (Toshiba corp. Tokio, Japón) a $80 \mathrm{kV}, 100 \mathrm{~mA}$ y $1 \mathrm{~s}$ de rotación, con la configuración de detectores $4 \times 4 \mathrm{~mm}$ y un tamaño de píxel de $0.468 \mathrm{~mm}$ para una matriz de $512 \times 512$ píxeles. El filtro de reconstrucción utilizado, FC043, no utiliza corrección por endurecimiento del haz para evitar modificaciones en la medida ante concentraciones elevadas de contraste, resultando en un índice de dosis volumétrico $\left(\right.$ IDTC $_{\text {vol }}$ ) de 516 mGy y un producto dosis por longitud (PDL) de 825,6 mGy.cm para el examen completo. Al paciente se le inyectaron $60 \mathrm{ml}$ de Iopamiro 300 (Bracco Imaging S.p.A., Milán, Italia) a una tasa de $6 \mathrm{ml} / \mathrm{s}$ mediante un inyector automático. A la inyección del agente de contraste le siguió un bolo de suero salino del mismo volumen y a la misma tasa.

Tanto el protocolo de adquisición de las imágenes como la preparación del paciente cumplieron con las recomendaciones del grupo Experimental Cancer Medicine Centre Imaging Network Group. ${ }^{12}$ La AIF se midió promediando la señal de los 4 vóxeles centrales de la arteria cerebral anterior izquierda. La localización de estos vóxeles fue determinada manualmente por un especialista en neurorradiología sobre la imagen obtenida 24 segundos tras la inyección de contraste, su localización se mantuvo estática durante todas las imágenes del estudio. Para la obtención de $c_{p}(t)$ se consideró como valor de cada píxel en ausencia de contraste al promedio de sus valores en las imágenes correspondientes a los 8 primeros segundos desde la inyección. El incremento de unidades Hounsfield (UH) fue la diferencia de cada imagen con estos valores promedio. El valor del incremento de UH se utilizó para interpolar (o extrapolar) de forma lineal la relación incrementos de UH y concentraciones de contraste, obteniendo así el valor de la concentración de contraste en la sangre $\left(c_{b}\right) . c_{p}$ está relacionado con $c_{b}$ mediante la siguiente ecuación:

$$
c_{p}(t)=\frac{c_{b}(t)}{\left(1-H C T_{v g}\right)}
$$

donde $H C T_{v g}$ se supuso con valor $0.42 .{ }^{13}$

\subsubsection{Caracterización del agente de contraste}

Para conocer la relación entre la concentración de contraste y el incremento de unidades Hounsfield (UH) se prepararon 15 disoluciones en pipetas de 8.5 $\mathrm{ml}$ rebajando la concentración del lopamiro 300 desde los $300 \mathrm{mg} / \mathrm{ml}$ hasta el rango comprendido desde 0 a $10 \mathrm{mg} / \mathrm{ml}$. Se utilizaron incrementos de $0.2 \mathrm{mg} / \mathrm{ml}$ entre 0 y $1 \mathrm{mg} / \mathrm{ml}$ y de $1 \mathrm{mg} / \mathrm{ml}$ entre 1 y $10 \mathrm{mg} / \mathrm{ml}$. Estas muestras se colocaron, de una en una, en el centro de un maniquí de PMMA de $16 \mathrm{~cm}$ de diámetro y $16 \mathrm{~cm}$ de longitud como se muestra en fig. 2, explorándose con el mismo protocolo que el usado para adquirir las imágenes de las que se obtuvo la AIF. Esta prueba se repitió con las muestras colocadas en un agujero a $1 \mathrm{~cm}$ de la periferia. Usando los valores en la región circular situada del centro de las muestras y alejada del borde del vial en el corte central del eje lon-
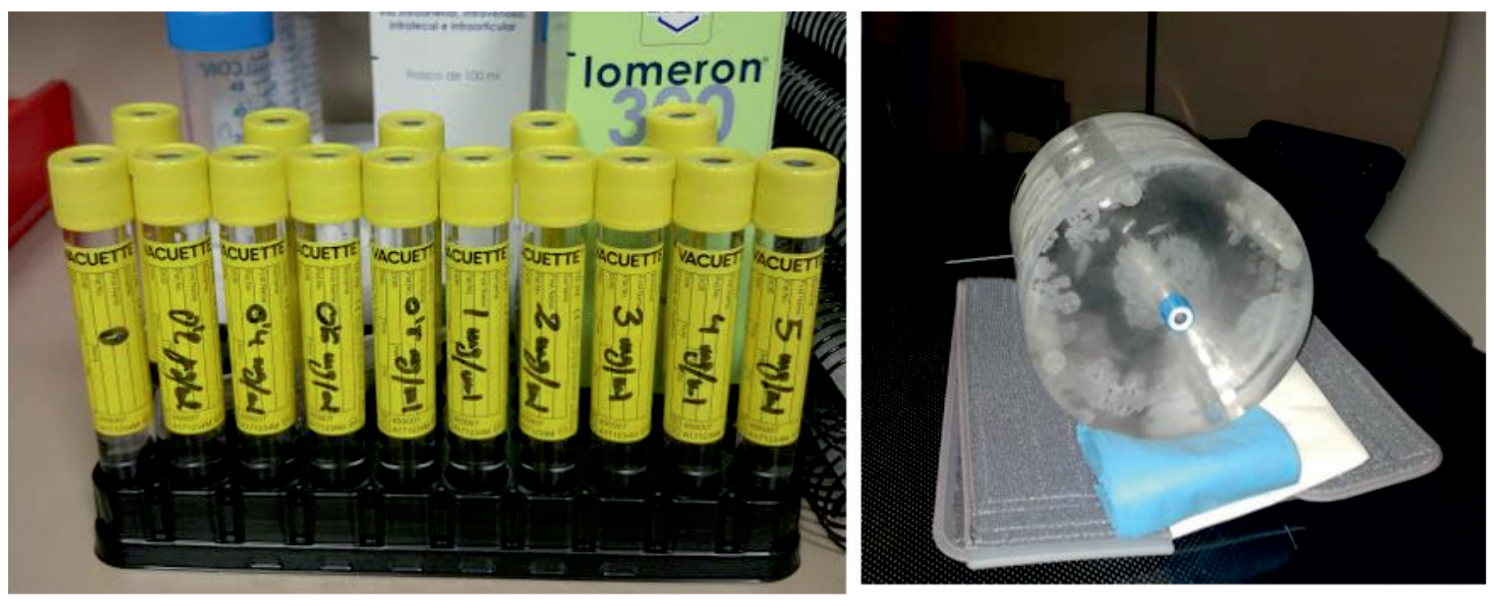

Fig. 2. Disoluciones con distintas concentraciones de contraste y montaje para la medida del incremento de UH. 
Tabla 1. Valores de prueba para los parámetros del modelo. En negrita se resaltan los valores que se pueden esperar en la práctica clínica habitual. ${ }^{14}$

\begin{tabular}{c|l} 
Parámetro & \multicolumn{1}{|c}{ Valores } \\
\hline$v_{p}(\mathrm{ml} / 100 \mathrm{ml})$ & $\mathbf{0 , 2} \mathbf{4}, \mathbf{6}, \mathbf{8}, \mathbf{1 0}, \mathbf{1 2}, 14,16,18,20$ \\
\hline$v_{e}(\mathrm{ml} / 100 \mathrm{ml})$ & $\mathbf{5}, \mathbf{1 0}, \mathbf{1 5}, \mathbf{2 0}, \mathbf{2 5}, \mathbf{3 0}, \mathbf{3 5}, \mathbf{4 0}, 45,50,55,60,65,70,75$ \\
\hline$K^{\text {trans }}(\mathrm{ml} / \mathrm{min} / 100 \mathrm{ml})$ & $\mathbf{1 0}, \mathbf{1 5}, \mathbf{2 0}, \mathbf{2 5}, \mathbf{3 0}, \mathbf{3 5}, \mathbf{4 0}, \mathbf{4 5}, 50,55,60,65,70,75,80$ \\
\hline$t_{d}(\mathrm{~s})$ & $\mathbf{0 , 1 , 2}$
\end{tabular}

gitudinal se ajustó una función lineal para relacionar el incremento de $\mathrm{UH}$ respecto al agua desionizada con la concentración de contraste.

\subsubsection{Imágenes de referencia}

Se compusieron unas hipermatrices de 4 dimensiones en los que cada elemento es el resultado de la operación indicada la ecuación (1) con el vector correspondiente a $c p(t)$, medido como se describe en el párrafo anterior y utilizando 0.2 para $H C T_{v p} .{ }^{13}$ Cada fila de estas hipermatrices correspondió a un valor de $K^{\text {trans }}$, cada columna a un valor de $v_{e}$, cada plano a un valor de $v_{p}$ y cada elemento de la cuarta dimensión a un instante de tiempo. Se simularon distintos retardos creando una hipermatriz para cada uno de ellos. Para simular los retardos $t_{d}$ se antepusieron ceros al vector $c p(t)$ y con ellos se obtuvieron varias hipermatrices, una para cada retardo simulado.

Los valores utilizados para generar los volúmenes se muestran en la tabla 1 .

\subsubsection{Medida del desempeño}

\subsubsection{Desempeño en condiciones ideales}

Para medir el desempeño en condiciones ideales del programa bajo pruebas se midió la exactitud y repetibilidad de sus resultados $\sin$ el uso del filtro PCA. Para esto se procesaron las imágenes generadas como se describió en el párrafo anterior. La exactitud se midió mediante la diferencia relativa de los mapas obtenidos y los valores de los parámetros que se usaron para generar las hipermatrices procesadas. Para comprobar si el programa ofrece siempre los mismos resultados ante las mismas imágenes se midió la repetibilidad de los resultados. La repetibilidad se midió repitiendo 5 veces el proceso y calculando la desviación típica de los resultados $\left(\sigma_{w s}\right)$. El coeficiente de repetibilidad $(C R)$ se definió según la recomendación de QIBA siguiendo la siguiente ecuación:7

$$
C R=1.96 \cdot \sqrt{2 \cdot \sigma_{w s}}
$$

\subsubsection{Desempeño en presencia de ruido}

Para evaluar el ruido presente en las imágenes DCE se realizó una exploración sobre un maniquí de cráneo (Imaging Solutions Ltd. Sidney, Australia) usando el protocolo descrito para la obtención de $c p(t)$. Para obtener un valor representativo de la desviación típica de un posible ruido blanco se utilizó la media de las desviaciones típicas en los $4 \mathrm{~cm}^{2}$ centrales del cerebro. Cada una de estas desviaciones típicas se calculó usando la señal definida por el valor del píxel a lo largo del tiempo.

Para medir el comportamiento del programa ante señales con ruido se repitió 500 veces el proceso de las
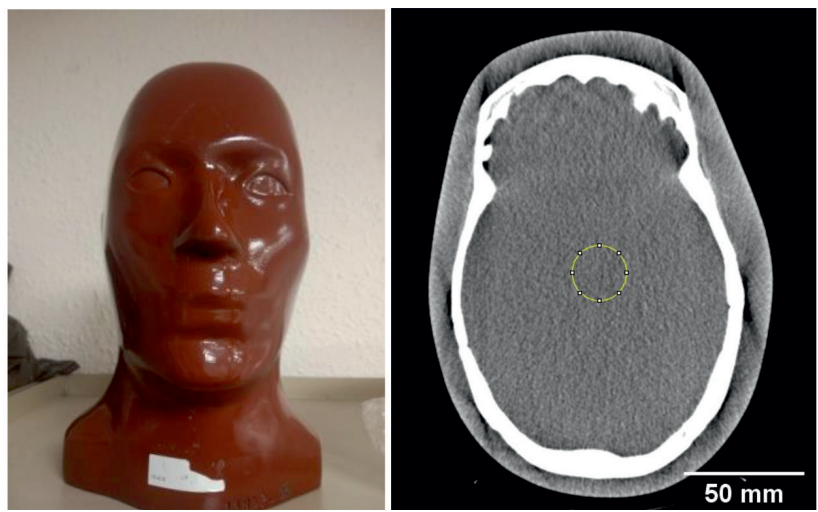

Fig. 3. Fotografía e imagen TC del maniquí obtenida con el protocolo de pruebas, se muestra en amarillo la ROI donde se obtiene la desviación típica. 
Tabla 2. Ecuaciones de ajuste de la relación entre incremento de UH y concentración de contraste, donde $c$ es la concentración de contraste. Entre paréntesis se muestra el intervalo de confianza al 95\% de los parámetros ajustados.

\begin{tabular}{c|c|c|c|c} 
Lugar & Ecuación & A [UH/(mg/ml)] & B [UH] & $\mathbf{R}^{2}$ \\
\hline Centro & $\Delta \mathrm{UH}=a \cdot c+b$ & $53.49(52.71,54.28)$ & $4.27(0.28,8.25)$ & 0.999 \\
\hline Periferia & $\Delta \mathrm{UH}=a \cdot c+b$ & $52.44(51.44,53.44)$ & $23.19(-19.87,28.25)$ & 0.999
\end{tabular}

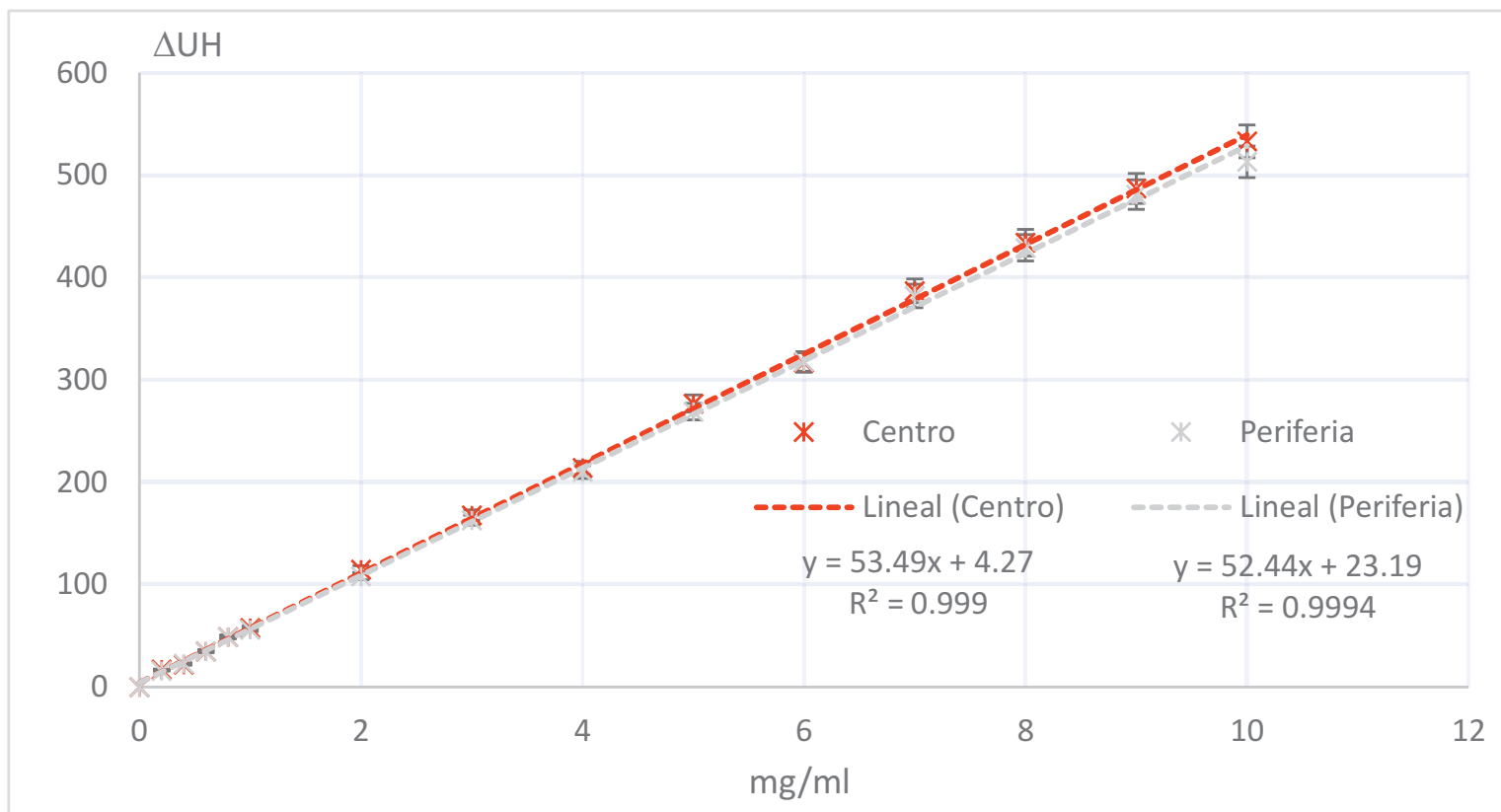

Fig. 4. Relación entre incremento de número CT y concentración de contraste medida para distintas disoluciones situadas tanto en el centro de un maniquí cilíndrico de $16 \mathrm{~cm}$ de diámetro de PMMA como en su periferia.

hipermatrices añadiéndoles ruido blanco y usando el filtro PCA. El ruido añadido a las hipermatrices $c_{t}(t)$ fue del tipo gaussiano, con media cero y con la desviación típica en $\mathrm{mg} / \mathrm{ml}$ correspondiente al incremento de UH medido en el maniquí de cráneo. La precisión de los resultados del programa para cada parámetro se definió como la desviación típica de los parámetros obtenidos como resultado en las 500 repeticiones del proceso de cálculo.

\section{Resultados}

\subsection{Caracterización del agente de contraste}

Las medidas de las disoluciones en el maniquí de PMMA a $80 \mathrm{kV}$ se ajustaron a las ecuaciones descritas en la Tabla 2 y se proporcionan en el archivo suplementario.
Los valores medidos y tabulados en el archivo suplementario se muestran en fig. 4 .

\subsection{Función de aporte arterial (AIF)}

En fig. 5 se muestra la curva medida en el paciente y convertida a concentración de contraste en sangre utilizando la función de ajuste obtenida para el centro del maniquí.

La curva mostrada en fig. 5 se convierte en $c_{p}(t)$ usando la ecuación (3) con $H C T=0.42$.

\subsection{Imágenes sintéticas de prueba}

En las siguientes ilustraciones (fig. 6, fig. 7 y fig. 8) se muestran las evoluciones en el tiempo de quince vóxeles representativos de las imágenes generadas. 


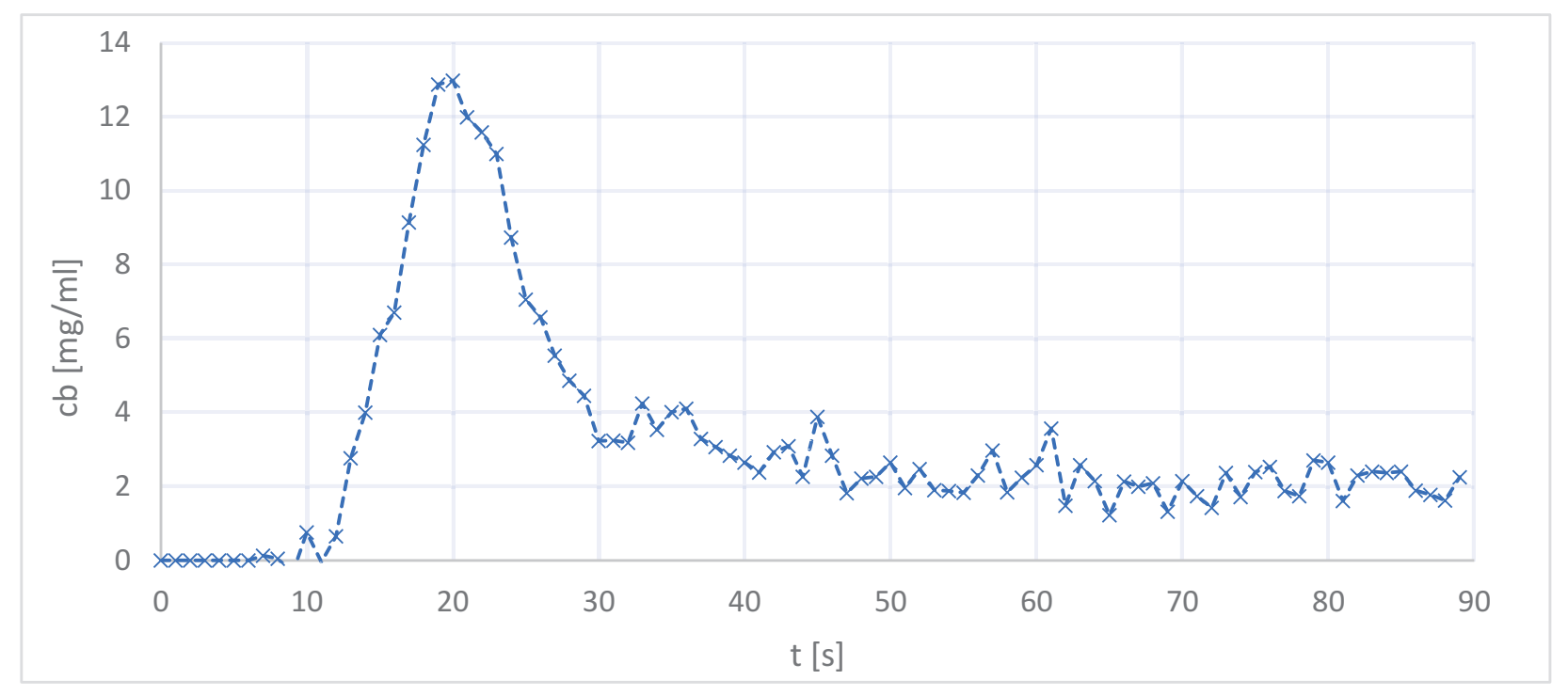

Fig. 5. Curva de concentración de contraste en sangre medida en los cuatro vóxeles centrales de la arteria la frontal derecha de un paciente con metástasis cerebral de cáncer epidermoide de pulmón.

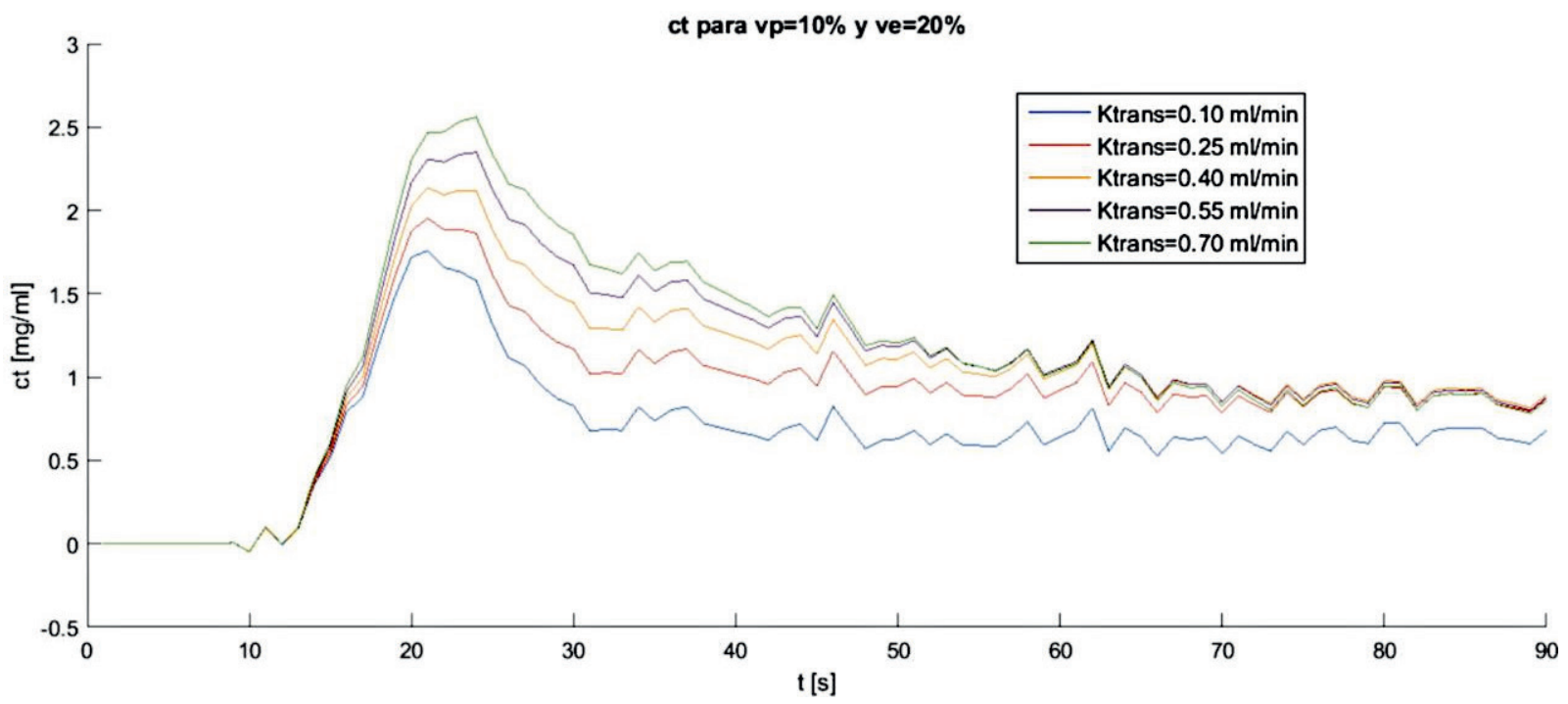

Fig. 6. Muestra de la evolución en el tiempo de cinco vóxeles de las imágenes sintéticas de prueba. En las gráficas se muestra de la concentración de contraste en el tejido $\left(c_{t}(t)\right)$ para distintos valores de tasa de intercambio de contraste $\left(K^{\text {trans }}\right)$.

\subsection{Exactitud y precisión del ajuste}

En las siguientes ilustraciones se muestra una selección de diferencias relativas entre los parámetros usados para generar las imágenes sintéticas de pruebas y los mapas obtenidos tras procesar las hipermatrices con el programa bajo pruebas. En fig. 9 se muestra la diferencia relativa entre mapa $K^{\text {trans }}$ y el valor real correspondiente a cada posición del mismo, en fig. 10 se muestran las diferencias relativas entre el mapa ve obtenido y los valores reales y en fig. 11 se muestra lo mismo para el mapa $v_{p}$. Los resultados detallados para todas las combinaciones posibles de los parámetros de entrada se pueden encontrar en el anexo I.

En las 5 repeticiones de las pruebas de exactitud para comprobar la repetibilidad se obtuvieron los mismos resultados, por lo que la desviación típica $\sigma_{w} \mathrm{y}$, por tanto, el CV es 0\% para todos los parámetros. 


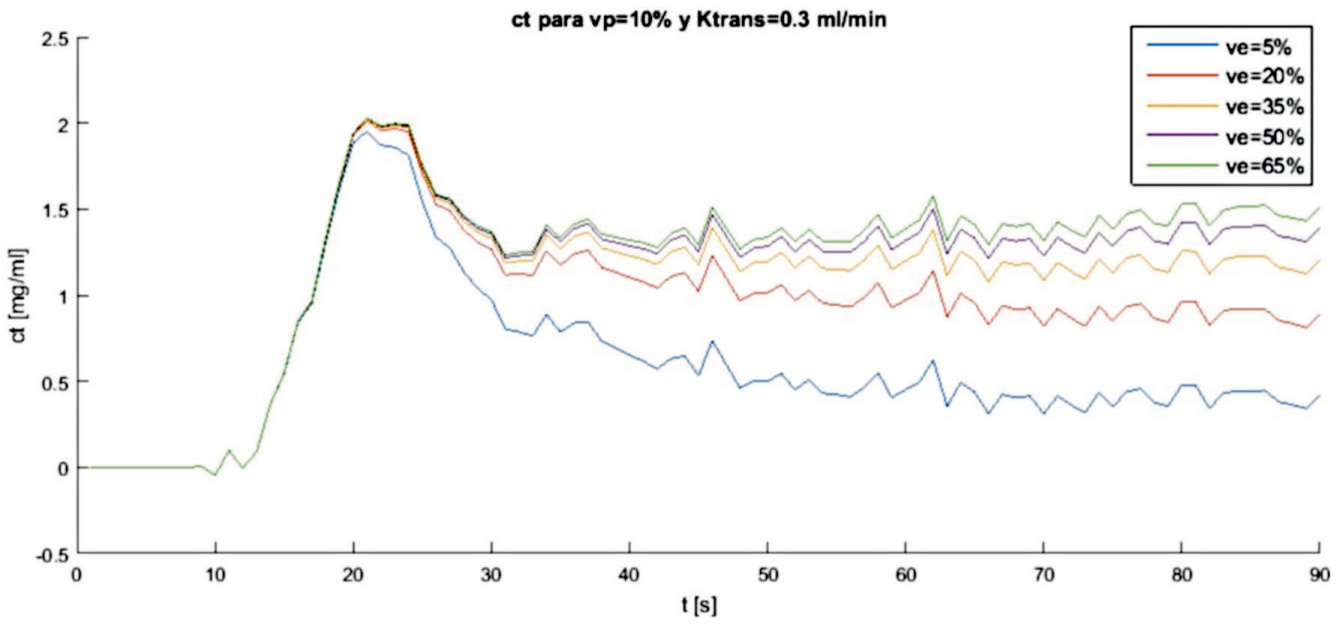

Fig. 7. Muestra de la evolución en el tiempo de cinco vóxeles de las imágenes sintéticas de prueba. En las gráficas se muestra de la concentración de contraste en el tejido $\left(c_{t}(t)\right)$ para distintos valores de fracción de volumen extracelular y extravascular $\left(v_{e}\right)$.

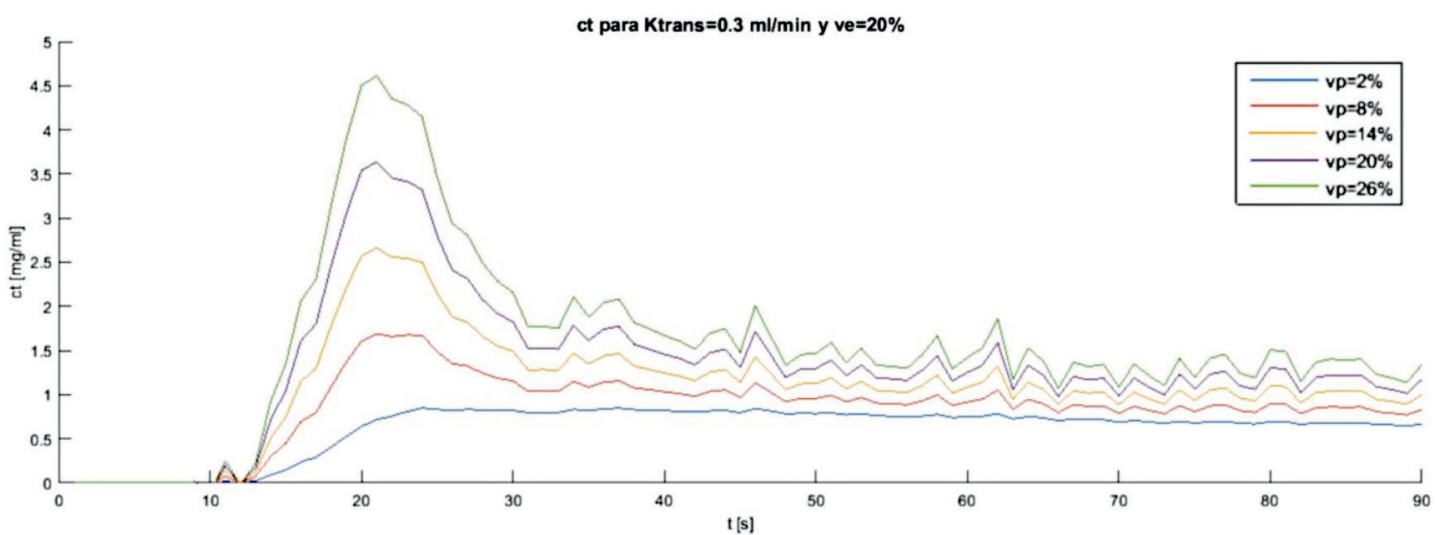

Fig. 8. Muestra de la evolución en el tiempo de cinco vóxeles de las imágenes sintéticas de prueba. En las gráficas se muestra de la concentración de contraste en el tejido $\left(c_{t}(t)\right)$ para distintos valores de fracción de volumen vascular $\left(v_{p}\right)$.
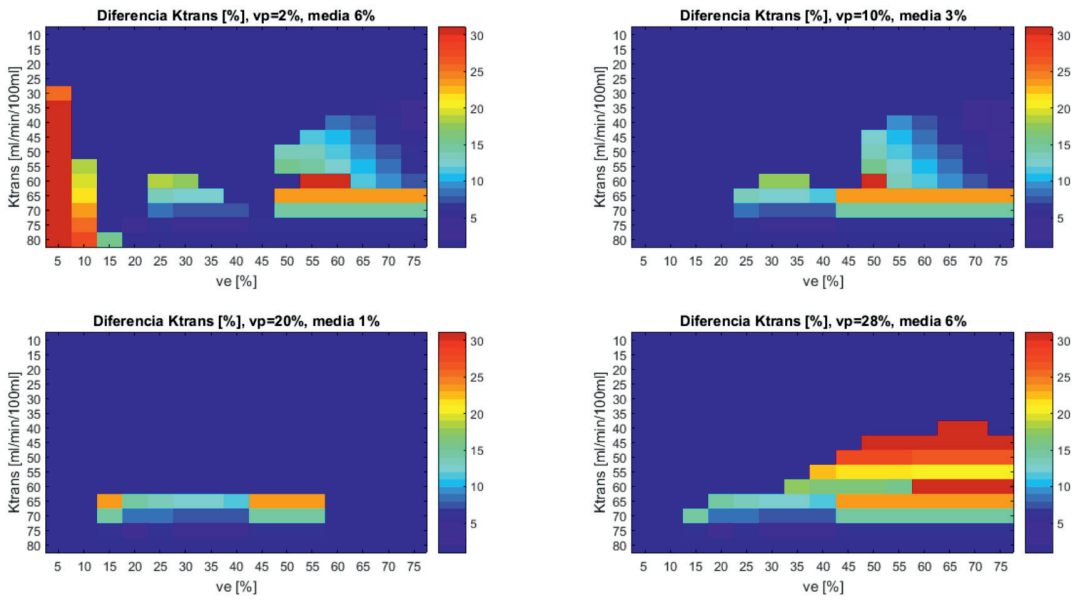

Fig. 9. Diferencias relativas entre el mapa $K^{\text {trans }}$ obtenido con el programa probado y los valores usados para generar las imágenes sintéticas de pruebas con un retardo simulado $t_{d}=1 \mathrm{~s}$. Cada imagen corresponde a un plano del mapa definido por el valor $v_{p}$ mostrado en su título y en los ejes de cada una de ellas se muestran los valores reales de $K^{\text {trans }}$ y $v_{e}$ que corresponden a cada fila y columna. 

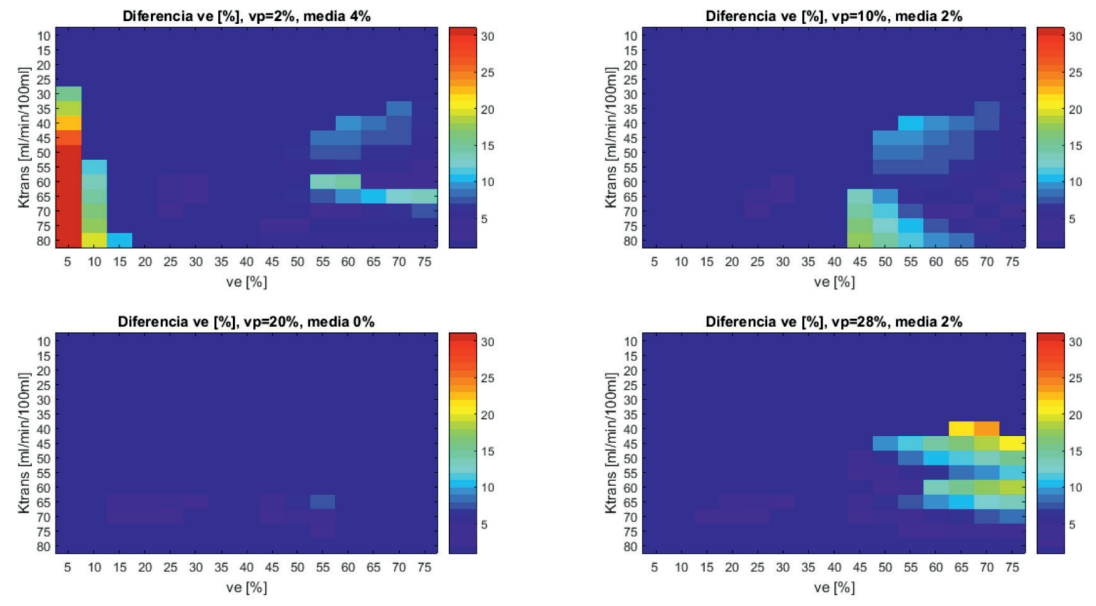

Fig. 10. Diferencias relativas entre el mapa ve obtenido con el programa probado y los valores usados para generar las imágenes sintéticas de pruebas con un retardo simulado $t_{d}=1 \mathrm{~s}$. Cada imagen corresponde a un plano del mapa definido por el valor $v_{p}$ mostrado en su título y en los ejes de cada una de ellas se muestran los valores reales de $K^{\text {trans }}$ y $v_{e}$ que corresponden a cada fila y columna.
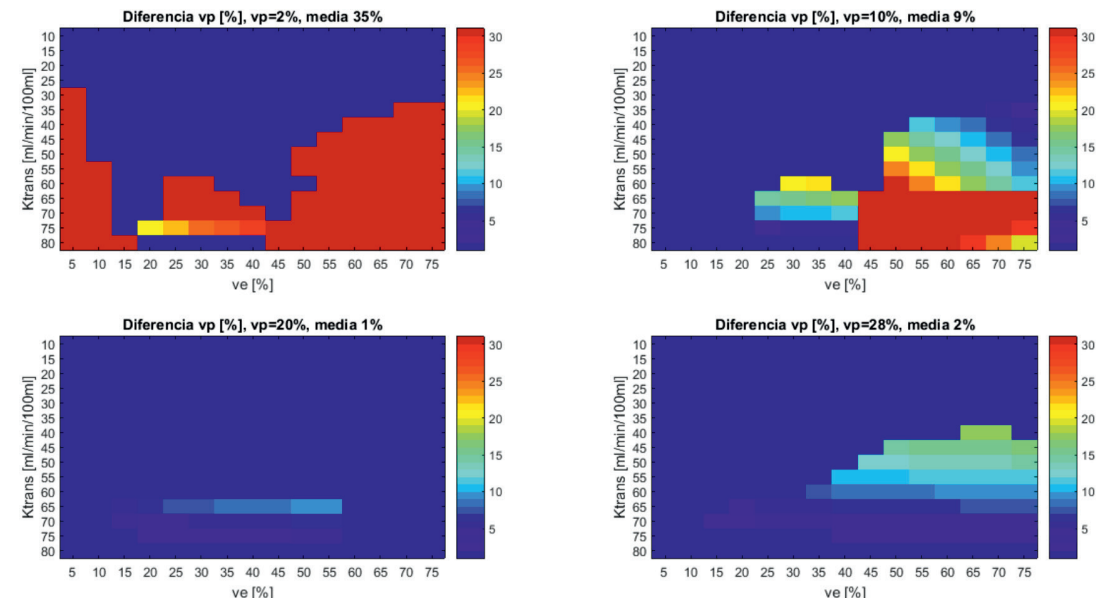

Fig. 11. Diferencias relativas el mapa $v_{p}$ obtenidos con el programa probado y los valores usados para generar las imágenes sintéticas de pruebas con un retardo simulado $t_{d}=1 \mathrm{~s}$. Cada imagen corresponde a un plano del mapa definido por el valor $v_{p}$ mostrado en su título y en los ejes de cada una de ellas se muestran los valores reales de $K^{\text {trans }}$ y $v_{e}$ que corresponden a cada fila y columna.

\subsection{Ruido añadido a las imágenes sintéticas de prueba}

En la serie dinámica de imágenes del maniquí de cráneo se midió una desviación típica media de 20 UH en el centroide del cráneo. Las desviaciones típicas se distribuyeron como se muestran en fig. 12.

A las series temporales mostradas en fig. 6, fig. 7 y fig. 8, se les añadió ruido blanco de $0.3 \mathrm{mg} / \mathrm{ml}$ de desviación típica correspondiente, según la ecuación descrita en la tabla 2, a las $20 \mathrm{UH}$ medidas en el maniquí.

\subsection{Precisión en presencia de ruido blanco}

En fig. 13, fig. 14 y fig. 15 se muestran los diagramas de cajas sobre los diagramas de dispersión de los resultados del proceso de las 500 series de imágenes sintéticas con ruido. Los resultados obtenidos se muestran como puntos grises y el diagrama de cajas muestra la mediana y los percentiles 25 y 75 . Las cruces indican resultados exóticos. En las tablas del anexo II se pueden encontrar el valor medio y la desviación típica de los resultados para cada combinación de parámetros de entrada. 


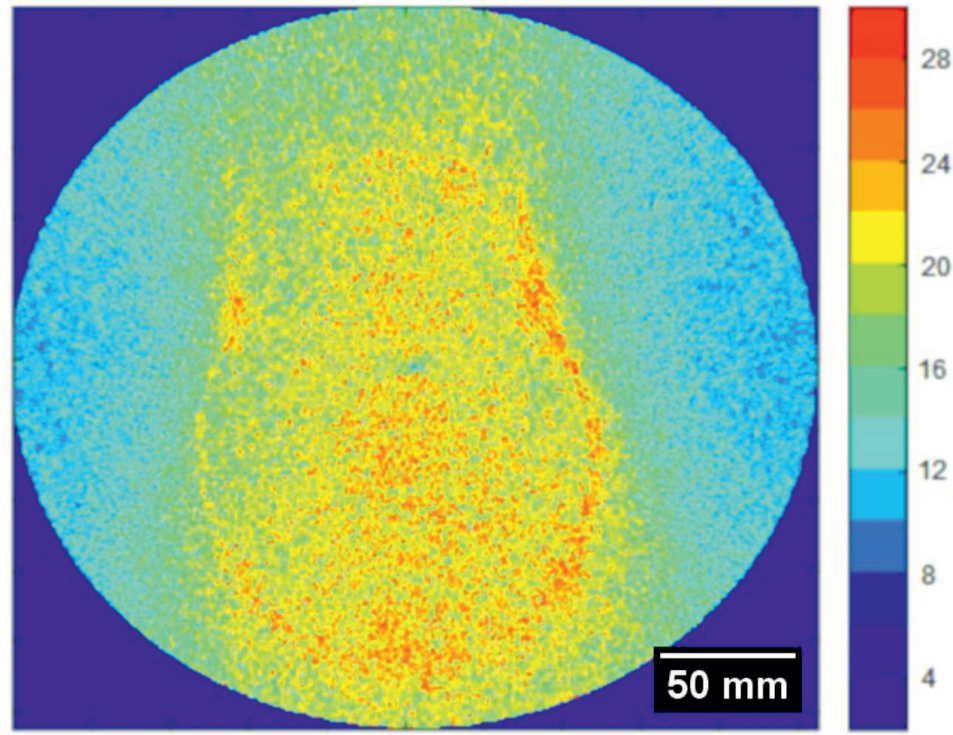

Fig. 12. Desviación típica medida en UH de las series temporales obtenidas para cada píxel de un maniquí.
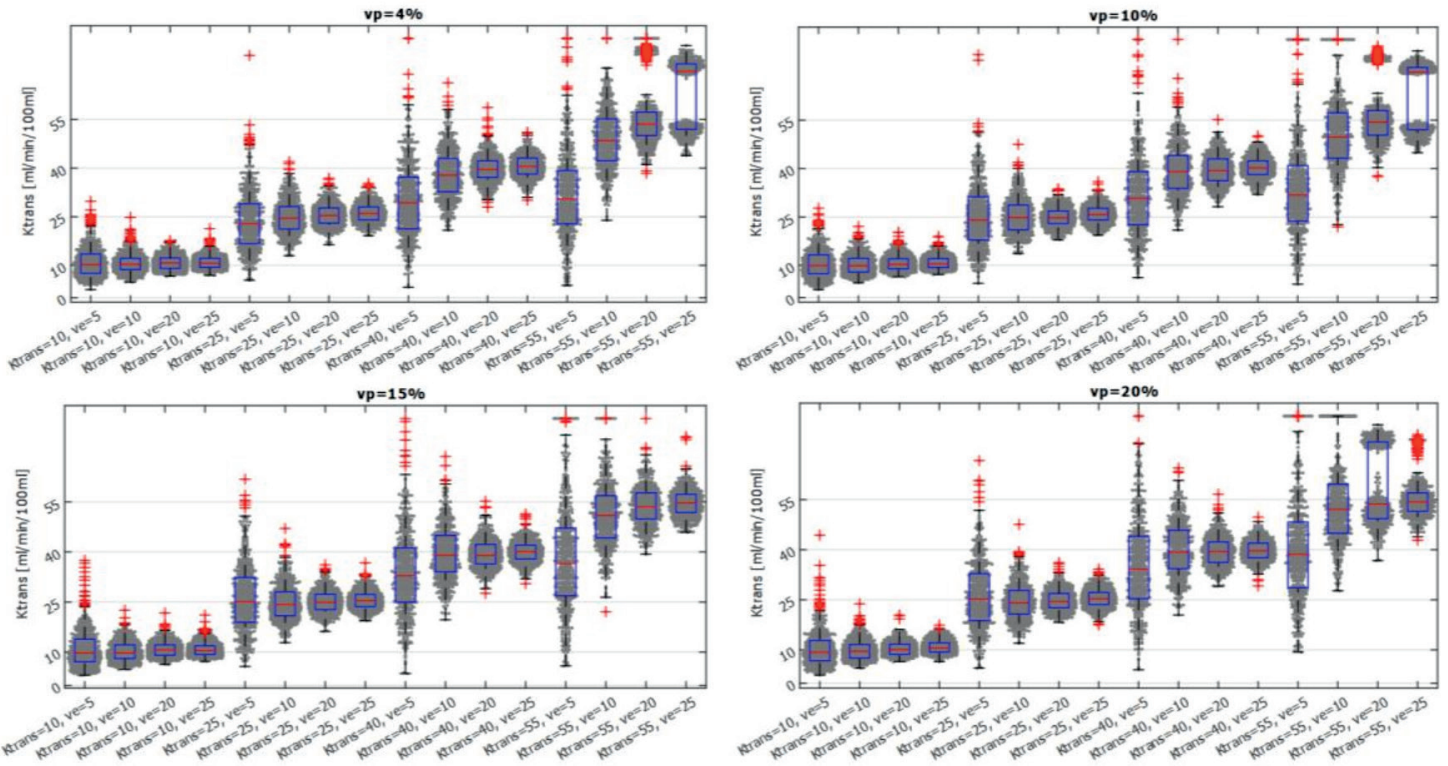

Fig. 13. Diagramas de dispersión y de cajas de los resultados del mapa $K^{\text {trans }}$ para distintas combinaciones de los parámetros de entrada.

\section{Discusión}

Los parámetros medidos al procesar las imágenes sintéticas de prueba en ausencia de ruido son exactos para la mayor parte de las combinaciones de valores de los parámetros, excepto para valores $v_{e}$ y $K^{\text {trans }}$ mayores de los esperados en la práctica clínica $\left(v_{e}>40 \%\right.$ y $K^{\text {trans }}$ $>40 \mathrm{ml} / \mathrm{min} / 100 \mathrm{ml}$ ). Esto es debido a que el programa probado utiliza en el proceso de ajuste como valores iniciales para los parámetros los previstos para lesiones cerebrales $\left(K^{\text {trans }}=25 \mathrm{ml} / \mathrm{min} / 100 \mathrm{ml}, v_{e}=15 \%, v_{p}=\right.$ $\left.5 \%, t_{d}=1 \mathrm{~s}\right)$. En las tablas mostradas en el anexo I se puede ver como la exactitud mejora a medida que los valores de los parámetros se encuentran más cerca de la combinación inicial, pues es menos probable encontrar mínimos relativos en la función objetivo en el camino desde la combinación de parámetros inicial hasta la utilizada para formar las imágenes. En fig. 16 

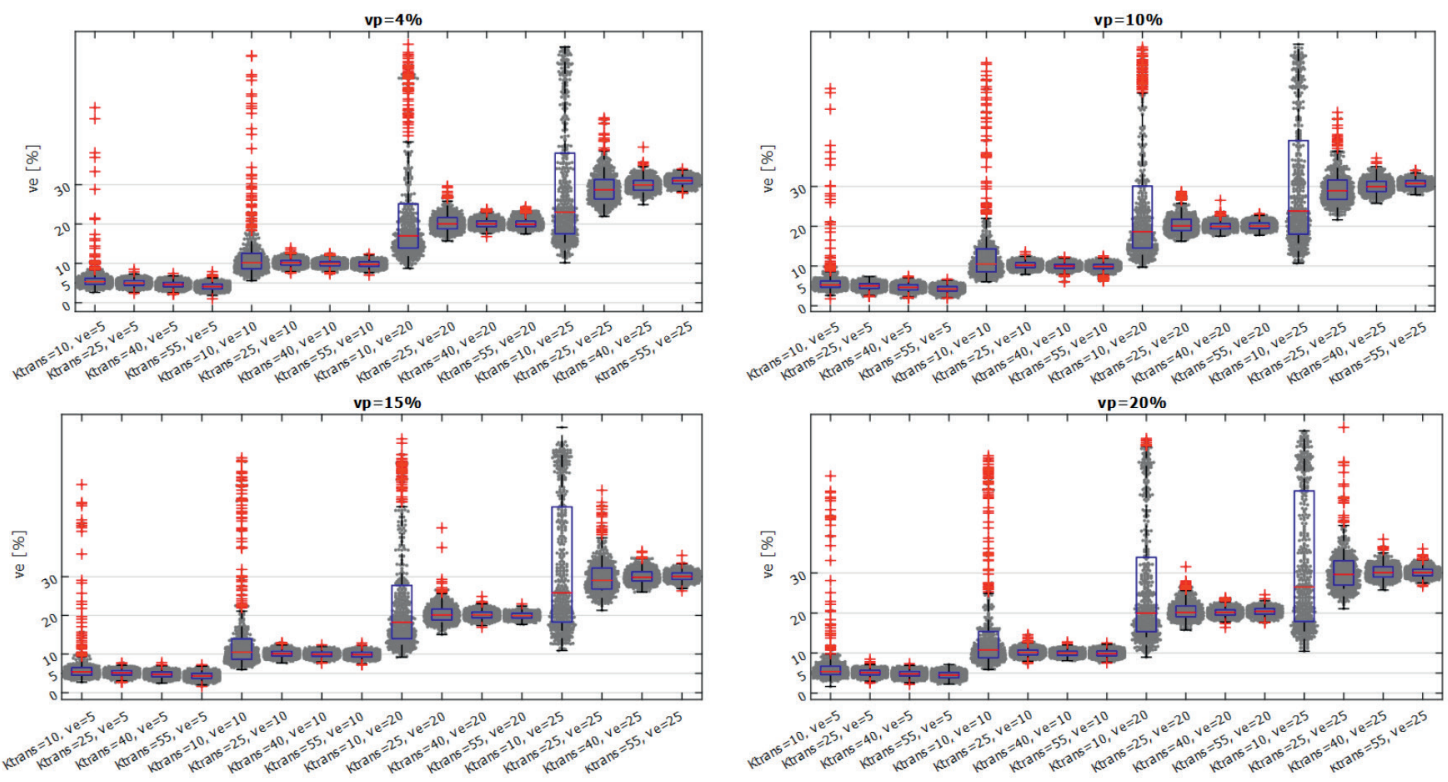

Fig. 14. Diagramas de dispersión y de cajas de los resultados del mapa ve para distintas combinaciones de los parámetros de entrada.
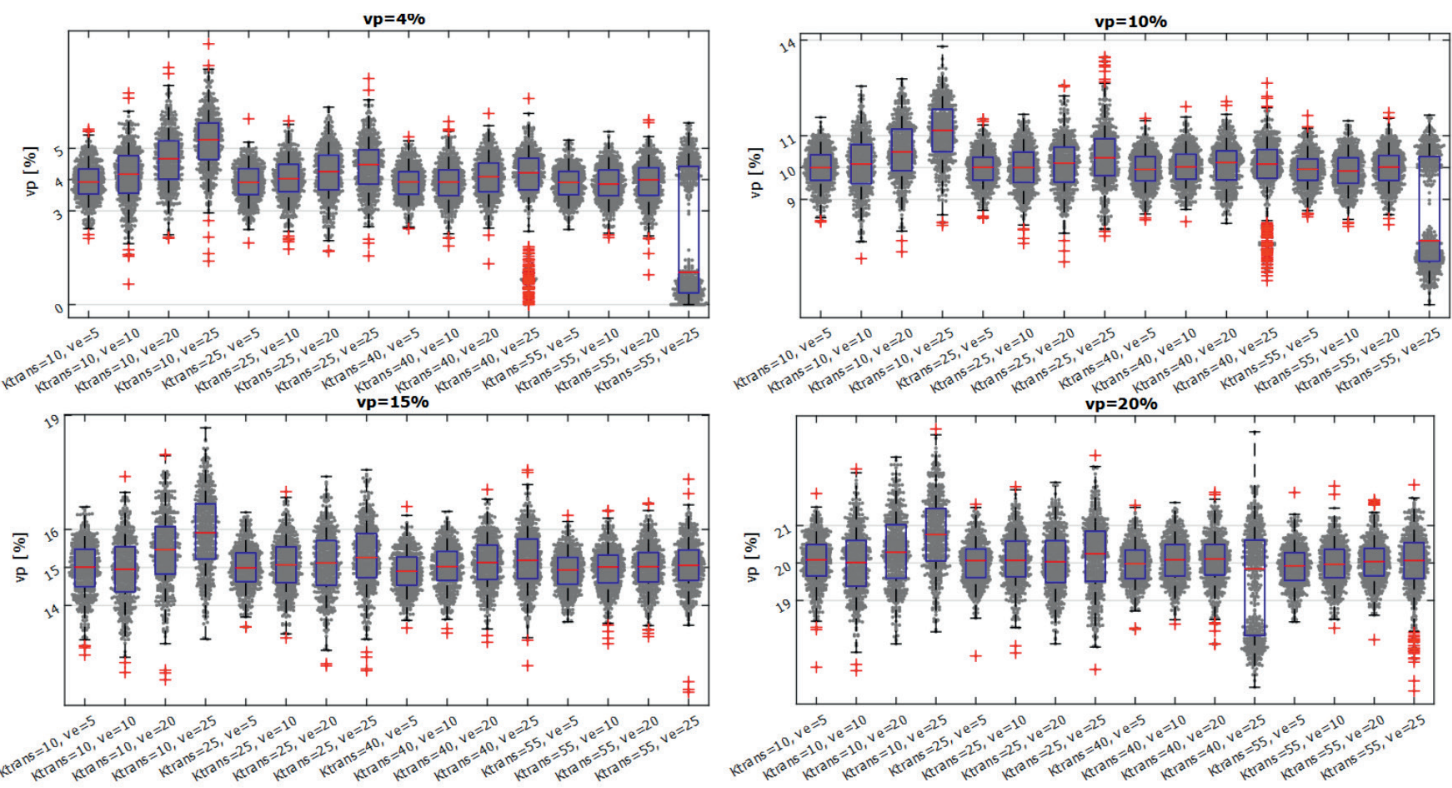

Fig. 15. Diagramas de dispersión y de cajas de los resultados del mapa $v_{p}$ para distintas combinaciones de los parámetros de entrada.

se muestra cómo las diferencias relativas menores se desplazan a los valores elevados de ve si se utiliza como valor de inicio $v_{e}=70 \%$.

Si se atiende a las diferencias mostradas en las tablas del anexo I en función del valor de $t_{d}$ utilizado para generar las imágenes sintéticas, también se puede observar que la exactitud mejora cuando el valor de $t_{d}$ es 1, coincidiendo con el valor inicial del proceso de ajuste. Por tanto, para hacer un uso óptimo del progra- ma sería recomendable estimar el retardo desde el lugar donde se mide la AIF hasta la lesión. Con unos $23 \mathrm{~cm} / \mathrm{s}$ de velocidad media en una arteria15, $t_{d}=1 \mathrm{~s}$ es una aproximación inicial aceptable para el tránsito desde un vaso cercano hasta la ROI más el tránsito por el interior de los vasos tortuosos de un tumor. De esta manera, puede suponerse que el ajuste sea óptimo siempre que la longitud transitada desde donde se mide la AIF hasta la lesión sea del orden de los 15-20 cm. 


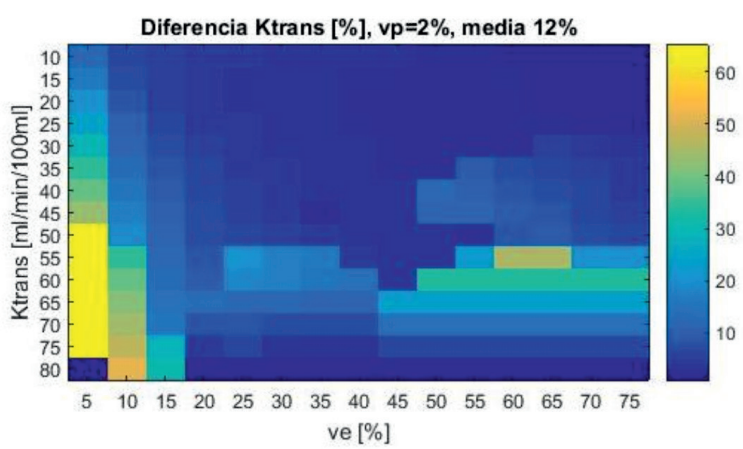

Fig. 16. Exactitud del mapa $K^{\text {trans }}$ para valores iniciales $v_{e}=$ $70 \%, v_{p}=12 \%$ y $K^{\text {trans }}=20 \mathrm{ml} / \mathrm{min} / 100 \mathrm{ml}$ y $t_{d}=0 \mathrm{~s}$. La imagen corresponde a un plano en el que el valor real de $v_{p}$ es el $2 \%$ mientras que los ejes $e$ muestran los valores reales de $K^{\text {trans }}$ y ve que corresponden a cada fila y columna.

El coeficiente de variación nulo de los resultados al procesar repetidas veces las mismas imágenes sintéticas de prueba permite al usuario volver a procesar las series de imágenes dinámicas en distintos momentos con la garantía de obtención de los mismos resultados.

En cuanto a los resultados obtenidos en imágenes con ruido, se puede observar como el parámetro más robusto es $v_{p}$, con unas desviaciones típicas muy pequeñas. Esto puede achacarse a que $v_{p}$ modifica principalmente la forma en el primer máximo $c_{t}(t)$, como puede verse en fig. 8. En los instantes cercanos al primer máximo es donde la relación entre la señal y el ruido es mayor y, por tanto, influye menos en el resultado del ajuste de $v_{p}$.

El parámetro que muestra unas desviaciones típicas mayores en presencia de ruido es $K^{\text {trans }}$, cosa que puede deberse a que es el parámetro que provoca menores diferencias en las señales $c_{t}$, como puede verse en fig. 9. Aunque $v_{e}$ es un parámetro que también se comporta de una manera bastante robusta en presencia de ruido, para valores muy pequeños (como el $5 \%$ ), deja de ser fiable al aparecer junto con $K^{\text {trans }}$ en el exponente de la ecuación 1 , de modo que es posible alcanzar mínimos locales de la función objetivo de ajuste para combinaciones de $K^{\text {trans }}$ y $v_{e}$ distintas de las reales.

De los resultados obtenidos se puede concluir que para exploraciones con $100 \mathrm{mAs}$, tanto $v_{p}$ como $v_{e}$ son parámetros robustos para la caracterización de tejidos, mientras que $K^{\text {trans }}$ lo es sólo para rangos en el entorno de los valores de inicio del ajuste. De esta manera, si se espera un rango reducido de valores de los parámetros del modelo, entonces es posible utilizar todos los parámetros para realizar un estudio que separe clases con diferencias pequeñas de parámetros. Para obtener un resultado óptimo es recomendable ajustar los valores de inicio a los esperados en el tejido. En caso de que se espere un rango muy amplio en los valores de los parámetros y las diferencias entre las clases del estudio sean reducidas, se puede optar por incrementar la carga por vuelta del tubo para reducir el ruido o no utilizar $K^{\text {trans }}$ si se aleja del valor de inicio.

Aun así, debido a que el filtro para la reducción de ruido basado en PCA modifica su comportamiento según el número de series utilizadas para obtener las componentes principales, es posible que el sistema sea más robusto cuando se utilicen ROI de mayor tamaño y con menor dispersión de formas que en las pruebas hechas en este estudio.

Puesto que el objetivo del estudio realizado es la evaluación del desempeño del programa bajo pruebas para en la tarea genérica de obtención de mapas paramétricos a partir de imágenes de TC, se han utilizado rangos extremadamente amplios de valores de los parámetros usados para generar las imágenes sintéticas de pruebas. Para evaluar el desempeño del programa en una situación específica podría ser útil generar maniquíes voxelizados, ${ }^{16}$ más parecidos a la situación en cuestión que una la hipermatriz genérica como la usada en este estudio, ya sea tanto por el rango de valores de los parámetros, como por su distribución en el espacio.

Una de las limitaciones principales del estudio es, hasta donde conocen los autores, la ausencia de un modelo contrastado para el ruido presente en la evolución temporal de la intensidad de cada vóxel. A pesar de esto, se comprueba ${ }^{16}$ que, para otros análisis cuantitativos realizados sobre imágenes de perfusión en TC, añadir el ruido medido en un maniquí en lugar del generado mediante una variable aleatoria gaussiana con la desviación estándar medida, genera un ruido en los mapas paramétricos más parecido al observado en mediciones en pacientes. Sin embargo, estos autores han comprobado mediante una prueba Kolmogorov-Smirnov ( $p=0.27)$ que el ruido observado en la región central del maniquí (cuya desviación típica se muestra en la sección 3.5), podría provenir de una fuente de tipo gaussiano.

A pesar de haber explorado el comportamiento del programa de ajuste para rangos de los parámetros del modelo que superan los esperados para cualquier localización, es posible que el cambio de la forma o amplitud de la AIF para localizaciones distintas de la utilizada para estas pruebas cause grandes diferencias en las formas de $c_{p}(t)$ y $c_{t}(t)$ para los mismos valores de los parámetros, lo que podría modificar el comportamiento del programa. Por este motivo, este estudio debe interpretarse como una evaluación del desempeño genérica y puede ser necesario realizar comprobaciones condicionadas a situaciones específicas. Para estas comprobaciones específicas se utilizarían tanto la relación entre incremento de UH y concentración de contraste para la energía del haz 
seleccionada, como las medidas de ruido y la AIF específicas para la región estudiada.

\section{Conclusiones}

El programa probado realiza correctamente la estimación de los parámetros de los tejidos a partir de la las imágenes DCE-CT, pudiéndose asegurar este extremo en las siguientes condiciones: que el ruido de las imágenes se encuentre por debajo de $20 \mathrm{UH}$, que la frecuencia de muestreo de las imágenes sea de $1 \mathrm{~s}$ y para 90 muestras (8 de ellas antes de la llegada del bolo de contraste), que se seleccionen los valores de inicio del proceso de ajuste al rango esperado en el tejido estudiado y que se estime previamente el retardo de llegada del bolo de contraste desde el lugar de medida de la AIF hasta la lesión estudiada.

\section{Bibliografía}

1. Ciudad Platero J, Guirado Llorente D, Sánchez-Reyes Fernández A, Sanjuanbenito Ruiz de Alda W, Velázquez Miranda S. Radiobiología Clínica. SEFM 2003. pp 12-20.

2. Egeland TA, Gulliksrud K, Gaustad JV, et al. Dynamic contrast-enhanced-MRI of tumor hypoxia. Magn Reson Med 2012;67(2):519-30.

3. Asenjo B, Navarro F, Arana E, Alberich-Vayarri A. Mapas de perfusión DCE-RM. Fundamentos físicos y aplicaciones clínicas. Madrid: Sociedad Española de Radiología Médica. 2019. ISBN: 978-84-09-12520-3.

4. Driscoll B, Keller H, Coolens C. Development of a dynamic flow imaging phantom for dynamic contrast-enhanced CT. Med Phys. 2011;38(8):4866-80.

5. Foltz W, Driscoll B, Lee SL, et al. Phantom Validation of DCEMRI Magnitude and Phase-Based Vascular Input Function Measurements. Tomography. 2019 Mar;5(1):77-89.
6. Low L, Ramadan S, Coolens C, et al. 3D printing complex lattice structures for permeable liver phantom fabrication. Bioprinting. 2018;10:e00025.

7. Shukla-Dave A, Obuchowski NA, Chenevert TL, et al. Quantitative imaging biomarkers alliance (QIBA) recommendations for improved precision of DWI and DCE-MRI derived biomarkers in multicenter oncology trials. J Magn Reson Imaging. 2019;49(7):e101-e21.

8. Sourbron SP, Buckley DL. Classic models for dynamic contrast-enhanced MRI. NMR Biomed. 2013;26(8):1004-27.

9. Tofts PS, Brix G, Buckley DL, et al. Estimating kinetic parameters from dynamic contrast-enhanced T(1)-weighted MRI of a diffusable tracer: standardized quantities and symbols. J Magn Reson Imaging 1999;10:223-32.

10. R Core Team (2013). R: A language and environment for statistical computing. R Foundation for Statistical Computing, Vienna, Austria. http://www.R-project.org/.

11. Balvay D, Kachenoura N, Espinoza S, et al. Signal-to-Noise Ratio Improvement in Dynamic Contrast-enhanced CT and MR Imaging with Automated Principal Component Analysis Filtering. Radiology. 2011;258(2):435-45.

12. Miles KA, Lee TY, Goh V, et al. Current status and guidelines for the assessment of tumour vascular support with dynamic contrast-enhanced computed tomography. Eur Radiol. 2012; 22:1430-41.

13. Calamante F, Ahlgren A, van Osch MJ, et al. A novel approach to measure local cerebral haematocrit using MRI. J Cereb Blood Flow Metab. 2016;36(4):768-80.

14. Schmitz S, Rommel D, Michoux N, et al. Dynamic contrastenhanced computed tomography to assess early activity of cetuximab in squamous cell carcinoma of the head and neck. Radiol Oncol. 2015;49(1):17-25.

15. Miyazawa T, Shibata S, Nagai K, et al. Relationship between cerebral blood flow estimated by transcranial Doppler ultrasound and single-photon emission computed tomography in elderly people with dementia. J Appl Physiol. 2018;125(5):1576-84.

16. Manniessing R, Brune C, van Ginneken B, et al. A 4D CT digital phantom of an individual human brain for perfusion analysis. Peer J. 2016;4:e2683. 


\section{imagine}

